\title{
Surgery for chronic pancreatitis: correspondence
}

\author{
Rujittika Mungmunpuntipantip ${ }^{1} \cdot$ Viroj Wiwanitkit $^{2}$
}

Received: 2 February 2022 / Accepted: 23 February 2022 / Published online: 27 February 2022

(c) The Author(s), under exclusive licence to Springer-Verlag GmbH Germany, part of Springer Nature 2022

\section{Dear Editor,}

We would like to comment on the publication "Surgery for chronic pancreatitis: the comparison of two high-volume centers reveals lack of a uniform operative management? [1]." Surci et al. concluded that a study of two high-volume hospitals' surgical attitudes toward chronic pancreatitis revealed that a standard approach to this condition is still lacking [1]. Although surgery can be conducted in specialist clinics with outstanding results, Surci et al. cautioned that it should always be carefully examined because it must be tailored to unique clinical settings and individual patients [1]. A question that has arisen is whether a common guideline for case management is required. In general, a practical standard guideline should exist, and there should be little variation. It is difficult to establish a consistent operational management system. It may be necessary to reach a consensus, and the Delphi technique survey may be used. Drewes et al. [2] published a recent paper that is a nice example of such an endeavor. The guideline, however, must be flexible. A special guideline for the treatment of chronic pancreatitis with a specific variety may also be established.

\section{Declarations}

Conflict of interest The authors declare no competing interests.

\section{References}

1. Surci N, Bassi C, Salvia R et al (2021) Surgery for chronic pancreatitis: the comparison of two high-volume centers reveals lack of a uniform operative management. Langenbecks Arch Surg 406:2669-2677. https://doi.org/10.1007/s00423-021-02335-1

2. Drewes AM, van Veldhuisen CL, Bellin MD, Besselink MG, Bouwense SA, Olesen SS, van Santvoort H, Vase L, Windsor JA (2021) Assessment of pain associated with chronic pancreatitis: an international consensus guideline. Pancreatology 21(7):1256-1284

Publisher's note Springer Nature remains neutral with regard to jurisdictional claims in published maps and institutional affiliations.
Rujittika Mungmunpuntipantip

Bangkok, Thailand

Dr DY Patil University, Pune, India 